\section{Re: Pregnancy Care: An Apprenticeship for Palliative Care?}

To the Editor: Thank you for an insightful piece ${ }^{1}$ on the beginning and end of life- one that helps draw comparisons between fields where few would find any similarities to exist. The table included at the end of the article could be applied across many fields and is one I will use in teaching often. One of the clearest similarities between pregnancy and care at the end of life is the unpredictable timing of the event. It can bring comfort to families to understand that things happen in their own time. I also compare how death is one of the many challenges we face in life, much like becoming a parent is an important challenge that changes who we are.

And to the Fournal of the American Board of Family Medicine, thank you for making this important piece free to the public. I also signed up to receive your RSS feed online. What a great tool for accessing your journal!

Christian T. Sinclair, MD Kansas City Hospice and Palliative Care Kansas City, MO csinclair@kchospice.org

\section{Reference}

1. Clark WD. Pregnancy care: an apprenticeship for palliative care? J Am Board Fam Med 2008;21:63-5.

The above letter was referred to the author of the article in question, who offers the following reply.

\section{Response: Re: Pregnancy Care: An Apprenticeship for Palliative Care?}

To the Editor: I appreciate the kind words of Dr. Christian Sinclair regarding my article "Pregnancy Care: An Apprenticeship for Palliative Care?" published in the Fournal of the American Board of Family Medicine in January 2008. ${ }^{1}$ In the months after the publication of the article, I received e-mails from physicians and nurses both within and outside the United States expressing appreciation for its content. Respondents included a nurse mid-wife educator from Israel who told me she planned to use the article to teach her mid-wife students. Her expressed intentions seem to give credence to Dr. Sinclair's observation that the article's content has broad applicability within health care education.

Although the practice of medicine has innumerable opportunities for meaningful communication, it is "these two sacred spaces" ${ }^{2}$ of birth and death that deserve and demand the best of what we can give as compassionate and empathic physicians.

William Clark, MD

Mercy Medical Center-North Iowa

Mason City, IA

clarkw@mercyhealth.com

\section{References}

1. Clark WD. Pregnancy care: an apprenticeship for palliative care? J Am Board Fam Med 2008;21:63-65.

2. Osborn JS. Easter Sunday in the ladies' room. Rapid Response, J Am Board Fam Med, January 8, 2008. Available at http://www.jabfm.org/cgi/eletters/21/1/63. Accessed August 29, 2008.

\section{Re: Improving Performance in Prevention}

To the Editor: Dr. Newton's commentary "Improving Performance in Prevention" ${ }^{1}$ deserves clarification. I believe he means disease detection and misused the term "prevention." Mammograms detect hopefully early enough to effect a curative treatment. Mammograms don't "prevent." Prevention is more of a population concept and thus, physicians have difficulty with the application to individuals regardless of interest. Prevention has a long history of success when governments become involved (sanitation, etc), and less success on an individual basis (prevention is hard to study on individual patients). This struggle brings to mind a long-standing battle in the history of medicine. The history of medicine has many caveats for today. For instance the Caduceus is not the appropriate symbol of medicine. The Caduceus is actually the symbol of Mercury in mythology and the Caduceus has been used as a symbol of commerce not medicine. The correct symbol is the Staff of Aesculapius (Asclepios). In addition, mythical medicine struggles continue today. The daughters of Aesculapius, (the god of healing), Hygeia (goddess of health), and Panacea (goddess of healing) were always at odds. Hygeia promoted hygiene and prevention, but panacea promoted treatment when ill. Physicians are much better trained to detect and treat than prevent. We should expect preventive medicine to be accomplished by governments and other population influences. I encourage all physicians to continue to emphasize prevention in our education of the individual patients, but we should concentrate on our skills in detection and treatment. Early disease detection is not prevention.

David O. Parrish, MD Bayfront Family Medicine Residency St. Petersburg, FL david.parrish@bayfront.org 